\title{
Keys for approaching community-based tourism
}

\author{
Claves del turismo de base local
}

\section{Esteban Ruiz Ballesteros}

Catedrático de Universidad. Dpto. de Antropología Social, Psicología Básica y Salud Pública. Univers. Pablo de Olavide.

Sevilla

eruibal@upo.es

\section{CLAVES DEL TURISMO DE BASE LOCAL}

MONOGRÁFICO COORDINADO POR ESTEBAN RUIZ BALLESTEROS (Universidad Pablo de Olavide)

\section{RESUMEN}

Este artículo introduce una reflexión teórica sobre el concepto de turismo de base local, destacando su acusado carácter normativo. No obstante, los múltiples estudios de caso disponibles reflejan una gran heterogeneidad y diversidad interna en las experiencias analizadas. Por todo ello, se insiste en la necesidad de estudiar empíricamente los factores y elementos que condicionan el desarrollo y sostenibilidad de este modo de organizar la actividad turística, procurando establecer estrategias comparativas entre casos. Finalmente, se proponen diferentes perspectivas de análisis y enfoques de investigación aplicados al turismo de base local que nos permitan profundizar sólidamente en su conocimiento.

\section{ABSTRACT}

This article offers a theoretical reflection on the concept of community-based tourism, highlighting its markedly normative character. However, the multiple case studies available reflect a great deal of heterogeneity and internal diversity with regard to the experiences analyzed. Hence, there is a need to study empirically the factors and elements that condition the development and sustainability of this way of organizing tourist activity, seeking to establish strategies for comparing different cases. Finally, the article proposes different analytical perspectives and research approaches applied to community-based tourism, which will allow us to gain a much stronger and more in-depth understanding of this phenomenon.

\section{PALABRAS CLAVE}

turismo de base local

KEYWORDS

community-based tourism

\section{Community-based tourism}

Tourism is a global business, a nigh on ubiquitous activity governed by a market that is supposedly inaccessible from a local level. There seems to be no doubt that tourism is directed by demand; supply is merely a demand-dependent response. Those who take this line assume that there is just one type of tourism and, therefore, they offer a univocal and flat interpretation of this activity: tourism as an exclusive manifestation of market interests and logics. By doing so they deny the possibility for alternatives or nuance. It is akin to believing there is just one way of farming crops or animals, or just one way of running industry. We know this is not the case, and the same goes for tourism. Furthermore, it is clear that the development of tourism -any tourism- implies an integral transformation of those places where it was previously not carried out, as would be the case with any other economic activity that appears out of nowhere or which undergoes substantial changes. This transformation caused by tourist activity cannot be elucidated on the basis of a mechanical and aprioristic reading; instead it requires an analysis that contemplates the uncertainty and ambivalence of complexity, considering human agency alongside the evident structural factors.

Just like any other activity, tourism can be organized in different ways, and its most conventional and hegemonic version, which places demand as the cornerstone of the model of tourism, can be nuanced with a perspective that is more firmly anchored to supply: a locally-oriented model of organization, management, and profit distribution. Naturally there can be no tourism without tourists; there is no activity without the attraction and satisfaction of demand, and in this respect, tourism will always be global. 
However, without contradicting this market principle, it is possible to define this tourist activity substantially in terms of local perspective and interests. All of this has an impact not so much on the nature of the tourist product -which might largely coincide with conventional offers and be encouraged through the market- but rather on the ways in which it is organized. It is, therefore, an activity that is geared towards the market -tourists-, but there is a unique reshuffling between supply and demand that fosters local protagonism in the organization, management, and benefits of tourism. Apparently, the phenomenon and product of tourism can be conventional, but the structure through which they are offered differs from the conventional norm.

These community-based tourist initiatives are crystallizing all around the world, under different names: community-based tourism and community-based ecotourism in English, and turismo comunitario in much of Latin America, but also ecoturismo comunitario, turismo rural comunitario, and even turismo de base local as a more general notion that can even incorporate different trends of rural tourism in Europe. The diversity of nomenclature reveals the relative expansion of this means of organizing the tourism business, which has been progressively incorporated by international bodies, governments, development and international cooperation agencies, NGOs, and even indigenous organizations, highlighting its versatility. This process has endowed community-based tourism (CBT) with a normative character that it initially lacked and which can be found easily in the different national and international legislation and regulations that seek not only to regulate it, but also to define it and specify its objectives (without concealing the concern to delimit growing competition with conventional tourist activities). Logically, from a research perspective, it is necessary to bear the normative dimension in mind at all times, but by the same measure it would be very dangerous to confuse it with the reality of these experiences of tourism.

We shall not examine this wealth of legislation here, but it is apropos to note the basic principles that form the foundation of public policies aimed at fostering this type of tourism. On the one hand, a link is established by way of a desideratum between community-based tourism and environmental sustainability, understanding that tourist activity that is anchored in the local sphere, particularly in protected areas or those of environmental interest, can help to modulate flows of tourists and make this activity more sensitive and environmentally aware by means of conservation policies. On the other, the direct and specific linking of tourist activity to the local community is presented as a guaranteed means of ensuring that the profits and benefits of tourism go back to said community. Thus, community-based tourism would be a vector for socio-economic development; hence its close relationship with pro-poor tourism and other similar strategies. Above all of this, in general, we must not forget about the concern felt by governments and organizations regarding the undesirable social and environmental effects of conventional tourism, shaped by global demand and major tourism corporations.

At a normative level, community-based tourism seems to offer as much an antidote as a panacea, and within the scientific arena itself there is a common echo when it comes to defining it and delimiting its objectives. Reviewing part of the relatively abundant literature on this issue (Amati 2013, Cañada 2014, George and others 2007, Hiwasaki 2006, Leksakundilok \& Hirsch, 2008, Manu \& Kuuder, 2012, MatarritaCascante and others 2010, Moore \& Rodger 2010, Mtapuri \& Giampiccoli 2014, Okazaki, 2008, Ramsa \& Mohd 2004, Ruiz-Ballesteros and others 2008, Stone \& Stone 2011, Tamir 2015, Tosun \& Timothy 2003), we find, with little nuance, a clear vision of what is expected of a community-based tourism initiative. One distinctive element highlighted is local protagonism, substantiated by the ownership and control over tourist activity. This circumstance takes on a more political level in the form of local empowerment. Secondly, reference is made to a defining commitment to the conservation of natural and cultural resources in the territory, placing both on the same level. The third prominent aspect of community-based tourism is its prioritization of the social and economic development of the community. Finally, focusing more on tourist activity itself, there is an expectation that this way of organizing tourism, closely linked to the local sphere, will foster a very individual and unique experience for visitors, grounded in the notion of authenticity, which impacts on the distinctive quality of this mode of tourism.

It is not hard to imagine that this normative umbrella might cover some very different individual experiences. The very notion of community-based tourism is becoming a polysemic if not openly lax term, which makes reference in practice to very different ways of organizing tourism. Indeed, the multiple case studies available give a ready account of this. Although there is always an evident presence of local participation in the planning, development, management, and profit distribution of tourism, the contexts and forms taken by these circumstances vary substantially. A little enquiry and comparison of case 
studies reveals a continuum that spans markedly collective experiences, in which tourist resources and businesses are owned and managed by the community, along with others that fundamentally include family-individually run initiatives with a greater or lesser degree of coordination. In any case, the level of local protagonism in tourist activity will serve to determine whether a specific experience is indeed a case of community-based tourism. On the other hand, the genesis of these experiences might well be very heterogeneous. There are cases that have emerged from explicit and planned strategies for the development of community-based tourism from the outset, with an evolution that encompasses collective processes of maturation and the progressive design of the project based on the collective ownership and/or usufruct of tourist resources. But equally there are others that have emerged more spontaneously, through individual and/or family-run initiatives that have become progressively interlinked and structured at different levels and by virtue of different interests until they have shaped a local model capable of structuring the individual and the collective in a complex way within the tourist business.

It is particularly worth reflecting on the exogenous or endogenous nature of these initiatives. It could be thought that community-based tourism responds to an exclusively local initiative and that as this exclusivity becomes diluted the authentically local meaning of the experience is lost. However, the participation of external agents in the development of community-based tourism is commonplace, with different levels of protagonism and intensity. The available literature does not contain any case studies in which there has been no type of external intervention in the emergence of projects. This does not mean that the local meaning and significance of the experience is lost per se, since the key resides in how the business is controlled and managed, and not exclusively in the nature of the participating agents. Furthermore, it is patently clear that any community would have difficulty in developing for itself a competitive tourist project without external advice, training, or initial funding. Undoubtedly the different degrees and levels of external intervention (sometimes dependence) become a net differentiating factor between community-based tourism experiences, also affecting their sustainability and true autonomy.

All these signs of heterogeneity and internal diversity in what we refer to as community-based tourism, resulting from the materialization of the same normative principles, merely serve to draw our attention to the need to investigate the phenomenon empirically in order to understand it adequately. It would be problematic -as a strategy- to look at each of the tourist experiences that claim to be "community-based" with the intention of finding sufficient development of their supposedly defining normative principles; rather, we would have to adopt a contrary or at the very least neutral stance: analyzing the tourist business conventionally and deducing whether we can trace these principles and to what extent. The most practical approach is to establish a dialogue between the manifest objectives of community-based tourism and the "realities" presented by different experiences. The normative does not always achieve empiric expression, especially when the principles of community-based tourism are set against the flow of conventional hegemonic tourism, questioning a substantial number of basic market principles as well as individualistic behaviours in social and economic functioning. Developing community-based tourism is no easy task.

Hence, general criticism emerges against this type of tourism with regard to the extent to which the principles that are assumed to be fundamental to CBT are attained; and even if these principles are questioned as such, they are truly achievable at reasonable levels. There are some successful cases, other evident failures, and even experiences wherein the self-definition as community-based tourism is highly questionable. All of this reveals a logical distance between the ideal aspiration of community-based tourism and the actual materialization of this aspiration. Does this distance represent a general discrediting of community-based tourism as a strategy to achieve empowerment, environmental and cultural conservation, local development, and quality tourism? Clearly not. Community-based tourism does contain a somewhat utopian component if you will, but no different to any other approach to tourism or for that matter to any other productive activity; its value lies in the horizon before which it places us, making us aware of the local sphere as legitimate custodian of tourist activity. Of course, it is perhaps debatable whether the development of community-based tourism is even positive for communities or whether, on the contrary, it could negatively and irreversibly transform them. From my point of view, tackling such diatribes requires more empirical-contextual analysis than theoretical-normative debate.

Hence, if there truly is interest in developing a fairer and more socio-environmentally aware tourism, we cannot limit our examinations to normative principles, in the manner of a desideratum, expecting that the clarity of their formulation leads to their materialization. Similarly, we cannot remain exclusively within the 
realms of empirical analysis of one case study after another, which might well reveal success stories and incontestable failures, but does not in itself allow us to gain a deeper general understanding of this type of tourism. To do this, we must take a strategic approach and tackle -through the comparison of case studies- the determination of factors that condition the development of normative principles that define community-based tourism. In this way, we will be able to understand this type of tourism properly, not in terms of its aspirations but rather its potential and the limits of its effective implementation. The theoretical and practical consequences of this approach are clear. On the one hand, it will allow us to know the keys to developing community-based tourism; and on the other, we can ascertain which elements must be taken into account when embarking on an experience of this nature. Ultimately, it is a case of conducting in-depth analysis to ascertain the conditions under which such ways of organizing tourism emerge and their possibilities for sustainability.

Since 2006, within the department of Social Anthropology at the Universidad Pablo de Olavide de Sevilla (Spain), we have been working on this strand of research through different projects in Latin America (Ecuador, Peru, Nicaragua, Costa Rica) and Spain (Andalusia), which we are currently drawing together as part of a Project on the Rhetorics of Nature and Community-Based Tourism: Strategies for Sustainability (SOC2012-33044), the results of which are reported partially in this publication, alongside eminent contributions from other researchers who also specialize in this field of research.

Our interest has always been to reflect on the conditioning factors of CBT at the level of local society, rather than examining the processes that are more directly linked with the tourist market and its organization. The aim is to unpick the way in which community-based tourism functions and operates from within the local societies themselves; hence our principally anthropological approach and the use of methodology that is firmly anchored to ethnography as a strategy for unravelling the day-to-day of this type of tourism. As the initial result of this research, we determined five factors that we understood to be key to the development of community-based tourism (Ruiz-Ballesteros and others 2008, Ruiz-Ballesteros \& Solís 2007): 1) the consistency of the community as a framework for collective action and decisionmaking; 2) the role played by local leaders in tourist projects; 3 ) the level and intensity of external intervention in the development of these initiatives; 4) the local appropriation of tourist phenomena and products; and finally 5) the ways in which local society is inserted, through tourism, into the market. We understood and still do understand -since the subsequent examination of more cases and spheres of study has not led us to question these factors, quite the contrary- that these factors help us to gain a full understanding of these types of tourist experiences, their origins, evolution, and also allow us to glimpse possible pathways of evolution. Furthermore, their analysis in terms of specific experiences allows us to elucidate the extent and degree to which the normative goals of CBT are achieved. However, these factors cannot be understood as causes that provoke effects, in this case the emergence and sustainability of community-based tourism. The matter is more complex than that. We are talking about factors and not about causes. The relationship between these factors and community-based tourism is more recursive than linear. These factors must be developed in order for a specific experience of CBT to be successful. But the factors do not have to develop previously; rather, through a recursive relationship, the tourism business and the different factors can be activated simultaneously. For example, the community building that is often associated with CBT does not have to be a prior condition; rather, paradoxically, the development of a CBT project can foster the progressive shaping of a community in terms of the capacity for collective action and decision-making (see Ruiz-Ballesteros 2009, Coca 2007). And similarly, the same can occur with the local appropriation of the tourist product, the development of leadership, and external intervention. These are necessary although not sufficient conditions, interconnected by means of a systemic and complex relationship (Ruiz-Ballesteros \& Fedriani 2009). The cases we have studied over the course of these years have corroborated the opportuneness of this perspective when it comes to understanding more appropriately the experiences of community-based tourism.

\section{Research strands into community-based tourism}

This continued work of research, analysis, and maturation has yielded different strands of research into community-based tourism. Together with the factors indicated above (Ruiz-Ballesteros et al., 2008), other elements and dimensions have been identified that are crucial for a comprehensive understanding of these tourist initiatives, facilitating a more complete approach to community-based tourism. All of this also 
allows us to draw more operational comparisons between cases. We are presenting them here so that they can be understood as converging analytical perspectives with blurred boundaries between them, but they do define research approaches that can be focused and made particular through the specific dimensions they reveal. To put it simply, the aim is to respond to the generic question: what should we be paying attention to when we study community-based tourism? By doing so, we can suggest the keys to gaining a more general understanding thereof.

\subsection{Community building}

In order to understand a CBT experience properly, we must carefully analyze the local society itself, focusing particularly on the influence it has on the development and management of tourism, and the effects of tourism on it.

When we attempt to unravel the keys to community-based tourist initiatives, and our gaze shifts from the explicitly tourist phenomenon to the functioning of local society, we often turn to notions such as social capital or human capital, built on the basis of attributes such as trust, reciprocity, commitment, and fairness, among others. The success of CBT experiences revolves around local development and social cohesion. In fact, these are its most salient normative objectives. Without rejecting the approaches that might be made from the perspective of social capital, we understand that the concept of community presents a much greater heuristic capacity. The notion of community, understood from a processual perspective that focuses on the capacity for collective action -hence our preference for the term community building-, allows us to understand collective functioning from an holistic perspective rather than an analytical fragmentation of its supposed components in the form of attributes. Community, as a concept, allows us to understand collective functioning from its totality: is a local society capable of developing collective action and to what extent? Obviously, this is tied to trust, cooperation, reciprocity, commitment..., but rather than lingering on each of these fragmented and static attributes and their hypothetical forms of ascertainment/measurement, we consider it more practical to analyze directly when, how and to what degree collective actions take shape and are developed effectively within a given local society (dynamic approach). That is where the capacity for community building resides, in this case closely linked to the development of a local model for the organization and management of tourism.

However, to do this, we must reconceptualize the notion of community so that it overcomes exclusive structural or symbolic definitions. It is imperative to understand that community is explained de facto through everyday processes and practices, and that the political and praxical dimensions are much more relevant than structural or symbolic ones (even encompassing them). To develop this analytical approach -which we consider crucial when studying community-based tourism- we would have to implement a much more complex and flexible perspective than the one usually brought into play when using the notion of community within the framework of social sciences. The aim is not to ascertain whether a collective possesses one attribute or another, but rather to analyze whether its dynamic creates community or not, understanding this notion as the capacity to foster collective action in the face of collective problems or interests (see Ruiz-Ballesteros 2012, Ruiz- Ballesteros \& Gálvez 2012, Ruiz-Ballesteros 2015, Ruiz-Ballesteros \& Cáceres-Feria 2016). This dimension is crucial in the context of any CBT experience. And precisely it is a crucial factor to understand the success or failure thereof: there can be no community-based tourism without a parallel process of community building. The very development of a collective tourist initiative contributes in itself to building a community as a process of collective action.

\subsection{Integration of tourism in the local economy}

It is fundamental to understand the role achieved by tourism in local economies. On the one hand, we will have to conduct a quantitative assessment, elucidating the weight of tourist activity in the local economy and the percentage of resources obtained that relate to tourism. To do this, we must bear in mind the monetary and non-monetary nature of many resources and economic activities (self-consumption). On the other, a more qualitative approach is required. We must capture the meaning of tourist activity set against all the community's economic activities as a whole: differences in the type of resources it fosters, differences in production relations, differences in the ways of relating with the environment and with other inhabitants. We must determine the extent and meaning with which tourism integrates into the economy, within all the locality's productive activities, and whether this produces any type of fracture that breaks rather than integrates the local socio-economic functioning. The generation of different and separate worlds within local societies -that of tourism and of the other activities- with different logics, forms, and 
consequences, does not normally foster a model of integration and social cohesion; quite the contrary in fact. Although it might be highly feasible, within domestic units and even for individuals themselves, for the duality between tourism and other activities to be a creative event in the form of pluri-activity that adds complexity and resilience to social life, it is not so if it produces a certain tourist "monoculture", leading to the abandonment of other activities, or if tourist activity is developed exclusively by certain groups whilst structurally excluding others. For all these reasons, we must unpick the economic and social meaning of tourist activity within experiences of community-based tourism.

\subsection{Rhetorics of nature}

The development of CBT is closely related with nature tourism or ecotourism. Therefore, its implementation turns the environment as such into a resource in an unprecedented way. In the majority of experiences, prior to the development of tourism, the environment had never before been seen and sold in the way it is starting to be now. This process entails the naturalization of the environment (RuizBallesteros and others 2009). Tied in with community-based tourism initiatives, we often find a process of heritagization that generates a very peculiar rhetoric in reference to that environment, which has habitually been the context for productive or extractive activities such as farming, hunting, logging..., and which tourism transforms, including a new gaze associated with a very specific rhetoric.

This process is, of course, not exclusive to $\mathrm{CBT}$; indeed it is commonplace in the development of all tourism related with nature as a product. However, it is necessary to examine the differences attained by these rhetorics of nature in experiences of CBT. Unlike other tourist initiatives, CBT very especially defends and advocates the role of humanity in the environment, to the extent that many experiences of CBT openly offer an anthropized nature, focusing on an environment that includes humans, and which even problematizes and contests the naturalizing discourses that exclude them. In any case, by paying close attention to the rhetorics and practices of nature in CBT initiatives, we will be able to gain a better understanding of the model of human-environment interaction that is behind the model of tourism in question, in turn contextualizing the way in which tourism is integrated into the economic activities of local society and the discourses of collective representation deployed (social identities).

\subsection{Commons}

Studying community-based tourism from the perspective of commons is a very fruitful strategy. Tourism is an activity that utilizes a very wide variety of different resources, with varying systems of ownership and access. These resources are seldom exclusive to tourism and are instead shared with other activities. When looking at community-based tourism experiences, the collective nature of the activity is frequently based on collective ownership/access to certain resources (forests, landscapes, sea...) that are also used for other activities in accordance with different logics (farming, fishing...). The collective management of these resources implies the existence of commons to which tourist activity is added. For that reason, it is important to analyze the effect of developing CBT on such commons pool resources and their management. However, the link between ownership and tourism goes further, since the development of CBT itself might well foster the generation of new commons, based precisely around tourist activity.

In this respect, analytically linking community-based tourism and commons (the logic of their governance and management) is a particularly eloquent approach to understanding how tourist activity is organized, which depends precisely on these resources and their communal nature. For that very reason there is growing interest in analyzing tourism from the perspective of commonly-owned resources at a general level and particularly with regard to CBT (Briassoulis 2002, Healy 2006, Holden 2005, Moore \& Rodger 2010, Stronza 2010, Ruiz-Ballesteros \& Gual 2012, Ruiz-Ballesteros \& Brondizio 2013).

\subsection{Identities and ethnogenesis}

The role played by CBT in reactivating or activating identities is a phenomenon that has now been universally accepted. Linked in some way to the debate about the authenticity of the tourist product (del Campo 2009), it is also associated, quite rightly, with more general conceptualizations such as the "tourist culture" (Picard 1992) and its effects on the construction of collective identities to the point that it shapes authentic processes of ethnogenesis such as that of the Manta people in Ecuador (Ruiz- Ballesteros 2009, Hernández-Ramírez \& Ruiz-Ballesteros 2011). Having overcome the tendency to consider tourism exclusively as a mere destroyer of identities and a source of cultural homogenization, it is time now to 
consider its role as a catalyst for other types of identarian processes of different kinds and magnitude. Tourism is not only a top-down process that filters down inexorably into the host societies; the inhabitants of the local societies in which tourism takes place are also capable of using tourism to position themselves in the market and in relation to the State by reflecting on their culture and appropriating tourist resources and products, which often involves explicit territorial and political claims. We must question the vision that proposes as the sole analytical perspective on community-based tourism its unquestionable -although not exclusive- capacity to destroy diversity and trivialize culture, in order to consider its capacity to contest external access to local resources (logging or mining, for example), and to reclaim difference in the market as well.

All of these processes have a very strong discursive dimension, which at the very least activates and catalyzes identities, and can even be capable of developing authentic processes of ethnogenesis that foster $21^{\text {st }}$ Century indigenism. Surprisingly, experiences of CBT sometimes play a very prominent role in all of this, one that needs to be analyzed.

\subsection{Governance}

Community-based tourism is linked with a specific model of managing tourist activity at a local level that, consequently, must be studied with sufficient depth of analysis. However, paradoxically, this analysis cannot be limited simply to the local level; a community-based tourism experience is practically unviable without external support at different levels (institutional and administrative structures, training, finance, commercial support...), both private and public. It is essential to analyze the relationship between each specific experience and the public sphere: legislation, administration. Community-based tourism has an endogenous seed that will have difficulty germinating and growing unless it is fertilized exogenously. For this reason, internal leadership and intra-community forms of organization must be a priority in terms of analysis, along with the different channels for external intervention (NGO, development agency, state government...) and the institutional/administrative network into which these community-based tourism initiatives are inserted. The particular form that these frameworks of governance can take could either be a catalyst for the viability of CBT experiences or, on the contrary, powerful vectors of an evident blockage, even though at a local level the initiative might be followed and encouraged with commitment and enthusiasm. Sketching out the framework of governance for each experience we study is a priority goal of analysis in order to understand properly the model of tourism organization we are studying and, therefore, the nature of the CBT initiative in question.

\subsection{Socio-Environmental sustainability}

The ultimate aim of our interest in CBT is simply to ascertain how it contributes to the sustainability of the socio-ecological system of which it is a part, and the extent to which tourist activity itself is sustainable. These two analytical goals are obviously related, but under no circumstances should they be confused with one another. The best way of tackling them is by means of analysis using the notion of socioecological resilience, understood as the capacity of a socio-ecological system to absorb alterations; overcoming processes of change while essentially maintaining the same functions, structures, and feedbacks (Walker \& Salt 2006: 32).

Community-based tourism is just one of the multiple activities that take place within a socio-ecological system. If we are concerned about the general resilience of the system (the resilience of the system as a whole to alterations that may occur), what we shall investigate in relation to CBT will be its peculiar role in maintaining and fostering this general resilience (for an example of these types of studies, see Ruiz-Ballesteros 2011). If we are concerned simply about the resilience of tourist activity itself (specific resilience), we will pay attention to a classic subject within studies on tourism: the sustainability of tourist activity itself in the face of alterations in the tourist market or the local economy, regardless of the path followed by the socio-ecosystem as a whole.

Clearly, the relationship between CBT and the general resilience of the socio-ecological system is much more relevant, since it involves analyzing the integral effect of tourism on local society and the territory it occupies. Furthermore, in some way it would include the specific resilience of tourist activity. To study this, we will have to take account of practically all the analytical dimensions we have set out here. The sustainability that CBT could foster is a complex and systemic function of its influence on community building, its insertion into the local economy, its modes of governance, its effects on collective identities 
and the discourses that represent the environment, as well as its contribution to the development of commons.

A large part of all these analytical dimensions are reflected, directly or indirectly, explicitly or implicitly, in the different case studies that make up this special issue. Sometimes these studies show how the local societies studied manage to develop a plausible model of community-based tourism; others stress the unsalvageable distance between the normative principles of CBT and what we find de facto in these localities. In any case, all the analyses provided show the opportuneness of focusing on certain keys in order to elucidate community-based tourism and develop on the back of this model certain strategies that allow us to understand it from within.

"From within" does not mean ignoring external agents or factors, but rather taking an analytical perspective that is in keeping with the objectives of CBT. Developing this type of tourism always implies a process of reflexivity within local societies, which should lead to their empowerment by staking their claim and self-managing their territories and resources. This process, if it develops in a solid and sustainable way, helps communities to claim a place within the State and within the market that, paradoxically, turns tourist initiatives into political tactics that need to be analyzed in all their complexity.

Acknowledgements: This text has been written as part of the project "Rhetorics of nature and community-based tourism: strategies for sustainability (CSO2012-33044, MINECO).

\section{References}

Amati, Cynthia

2013 "We all voted for it: experiences of participation in community-based ecotourism from the foothills of Mt Kilimanjaro", Journal of Eastern African Studies, no 7 (4): 650-670.

Briassoulis, Helen

2002 "Sustainable tourism and the question of the commons", Annals of Tourism Research, $\mathrm{n}^{\circ} 29$ : 1065-1085.

Cañada, Ernest

2014 Turismo comunitario en Centroamérica. Experiencias y aprendizajes. Managua, Editorial Enlace.

Coca Pérez, Agustín

2007 "Machacuyacu, turismo y organización comunitaria", in Esteban Ruiz-Ballesteros and Doris Solis (coords.), Turismo comunitario en Ecuador. Quito, Abya-Yala: 93-124.

Del Campo Tejedor, Alberto

2009 "La autenticidad en el turismo comunitario. Tradición, exotismo, pureza, verdad", in Esteban Ruiz Ballesteros and $\mathrm{M}^{\mathrm{a}}$ Augusta Vintimilla (coords.), Cultura, comunidad y turismo. Ensayos sobre el turismo comunitario en Ecuador. Quito, Abya-Yala: 41-116.

George, Brian (and others)

2007 "The Business of Community Based Tourism: A Multi-Stakeholder Approach", Tourism Issues, $\mathrm{n}^{\circ}$ 3: 1-19.

Healy, Robert

2006 "The commons problem and Canada's Niagara Falls", Annals of Tourism Research, n 33: 525-544.

Hernández-Ramírez, Macarena (and Esteban Ruiz-Ballesteros)

2011 "Etnogénesis como práctica. Arqueología y turismo en el pueblo Manta (Ecuador)", AlBR Revista de Antropología Iberoamericana, $\mathrm{n}^{\circ} 6$ (2):159-192.

Hiwasaki, Lisa

2006 "Community-Based Tourism: A Pathway to Sustainability for Japan's Protected Areas", Society and Natural Resources, $\mathrm{n}^{\circ} 19$ (8): 675-692. 


\section{Holden, Andrew}

2005 "Achieving a sustainable relationship between common pool resources and tourism: The role of environmental ethics", Journal of Sustainable Tourism, n 13: 339-352.

Leksakundilok, Anucha (and Peter Hirsch)

2008 "Community-based tourism in Thailand", in John Connell (ed.), Tourism at the grassroot.Villagers and visitors in the Asia-Pacific: 214-235.

Manu, Isaac (and Wuleka Kuuder)

2012 "Community-Based Ecotourism and Livelihood Enhancement in Sirigu, Ghana", International Journal of Humanities and Social Science, $n^{\circ} 2$ (18): 97-108.

Matarrita-Cascante, David (and others)

2010 "Community agency and sustainable tourism development: the case of La Fortuna, Costa Rica", Journal of Sustainable Tourism, no 18 (6): 735-756.

Mtapuri Oliver (and Andrea Giampiccoli)

2014 "Towards a comprehensive model of community-based tourism development", South African Geographical Journal, no 98: 154-168.

Moore, Susan (and Kate Rodger)

2010 "Wildlife tourism as a common pool resource issue: enabling conditions for sustainability governance", Journal of Sustainable Tourism, n 18: 831-844.

Okazaki, Etsuko

2008 "A Community-Based Tourism Model: Its Conception and Use", Journal of Sustainable Tourism, $\mathrm{n}^{\circ}$ 16 (5): 511-529.

Picard, Michel

1992 Bali: tourisme culturel et culture touristique. París, L'Harmattan.

Ramsa Yaman, Amat (and Abdullah Mohd)

2004 "Community-based Ecotourism: A New proposition for Sustainable Development and Environmental Conservation in Malaysia", Journal of Applied Science, nº 4 (4): 583-589.

Ruiz-Ballesteros, Esteban

2009 Agua Blanca. Comunidad y turismo en el Pacífico ecuatorial. Quito, Abya-Yala.

2011 "Socio-Ecological Resilience and Community-Based Tourism. An Approach From Agua Blanca, Ecuador", Tourism Management, no 32 (3): 655-666.

2012 "La vigencia de la comunidad. Prácticas para navegar en la globalización desde la periferia andina", Chungara. Revista Chilena de Antropología, no 44: 419-433.

2015 "Turismo de base local y comunidad, ¿una vinculación oportuna?", Revista Andaluza de Antropología, no 8: 19-44

Ruiz-Ballesteros, Esteban (and Cristina Gálvez García)

2012 "Community, common-pool resources and socio-ecological systems: Water management and community building in southern Spain", Human Ecology, nº 42 (6): 847-856.

Ruiz-Ballesteros, Esteban (and Eugenio Fedriani Martel)

2009 "Un análisis comparativo para el turismo comunitario: de la etnografía al grafo", in Esteban Ruiz Ballesteros and M. Augusta Vintimilla (coords.), Cultura, comunidad y turismo. Ensayos sobre el turismo comunitario en Ecuador. Quito, Abya-Yala: 433-457.

Ruiz-Ballesteros, Esteban (and Doris Solis) (coords.)

2007 Turismo comunitario en Ecuador. Desarrollo y Sostenibilidad Social. Quito, Abya-Yala.

Ruiz-Ballesteros, Esteban (and Eduardo Brondizio)

2013 "Building negotiated agreement: The emergence of community based tourism in Floreana (Galapagos Islands)", Human Organization, no 72 (4): 323-335. 
Ruiz-Ballesteros, Esteban (and Miquel Gual)

2012 "The emergence of new commons. Community and multi-level governance in the Ecuadorian coast", Human Ecology, $\mathrm{n}^{\circ}$ 40: 847-862.

Ruiz-Ballesteros, E. (and Rafael Cáceres)

2016 "Community-building and amenity migration in community-based tourism development. An approach from southwest Spain", Tourism Management, $n^{\circ}$ 54: 513-523.

Ruiz-Ballesteros, E. (and others)

2008 "Turismo comunitario en Ecuador. Comprendiendo el community-based tourism desde la comunidad", Pasos. Revista de turismo y patrimonio cultural, nº 6 (3): 399-418.

2009 "Naturalizing the environment. Perceptual frames, senses and resistance", Journal of Material Culture, $\mathrm{n}^{\circ}$ 14: 147-167.

Stone, Lesego Senyana (and Tibabo Moren Stone)

2011 "Community-based tourism enterprises: Challenges and prospects for community participation; Khama Rhino Sanctuary trust, Botswana", Journal of Sustainable Tourism, no 19 (1): 97-114.

Stronza, Amanda

2010 "Common management and ecotourism. Ethnographic evidence from the Amazon", International Journal of the Commons, $n^{\circ} 4: 56-77$.

Tamir, Meseret

2015 "Challenges and Opportunities of Community based Tourism Development in Awi Zone: A Case Study in Guagusa and Banja Woredas, Ethiopia", Journal of Tourism, Hospitality and Sports, n 11: 50-78.

Tosun, Cevat (and Dallen Timothy)

2003 "Arguments for Community Participation in Tourism Development", Journal of Tourism Studies, nº 14 (2): 2-11.

Walker, Brian (and David Salt)

2006 Resilience Thinking. Washington, Island Press. 